\title{
Correction to: Accurate position control of shape memory alloy actuation using displacement feedback and self-sensing system
}

Ermira Junita Abdullah ${ }^{1}$ (D) Josu Soriano ${ }^{2} \cdot$ Iñaki Fernández de Bastida Garrido ${ }^{2} \cdot$ Dayang Laila Abdul Majid $^{1}$

Published online: 7 January 2021

(C) Springer-Verlag GmbH Germany, part of Springer Nature 2021

\section{Correction to: Microsystem Technologies https://doi.org/10.1007/s00542-020- 05085-0}

Unfortunately, The line for one of the graphs (Mean Voltage vs Time for Displacement Feedback) in Fig. 14 does not appear in the published manuscript. The corrected figure is given below.

The original article can be found online at https:// doi.org/10.1007/s00542-020-05085-0.

Ermira Junita Abdullah

ermira@upm.edu.my

1 Department of Aerospace Engineering, Universiti Putra

Malaysia, Serdang, Malaysia

2 CS Centro Stirling, S. Coop, Aretxabaleta, Spain 
Displacement Feedback
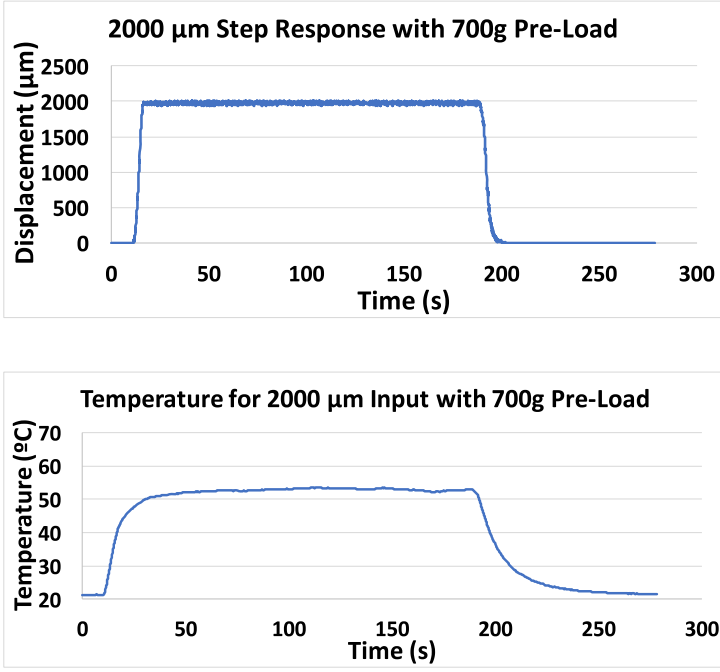

Mean Voltage for $2000 \mu \mathrm{m}$ with 700g Pre-Load

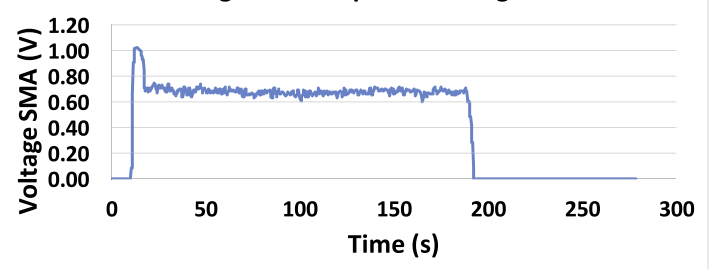

Resistivity for $\mathbf{2 0 0 0} \mu \mathrm{m}$ Input with 700g Pre-Load

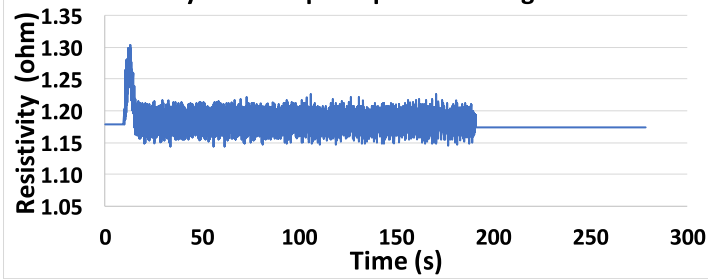

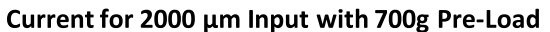

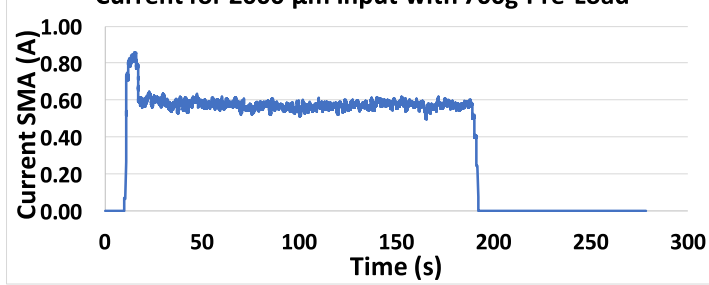

PID signal for $2000 \mu \mathrm{m}$ Input with $700 \mathrm{~g}$ Pre-Load

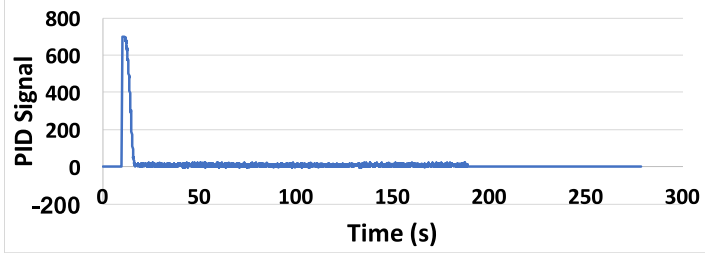

Self-sensing Feedback
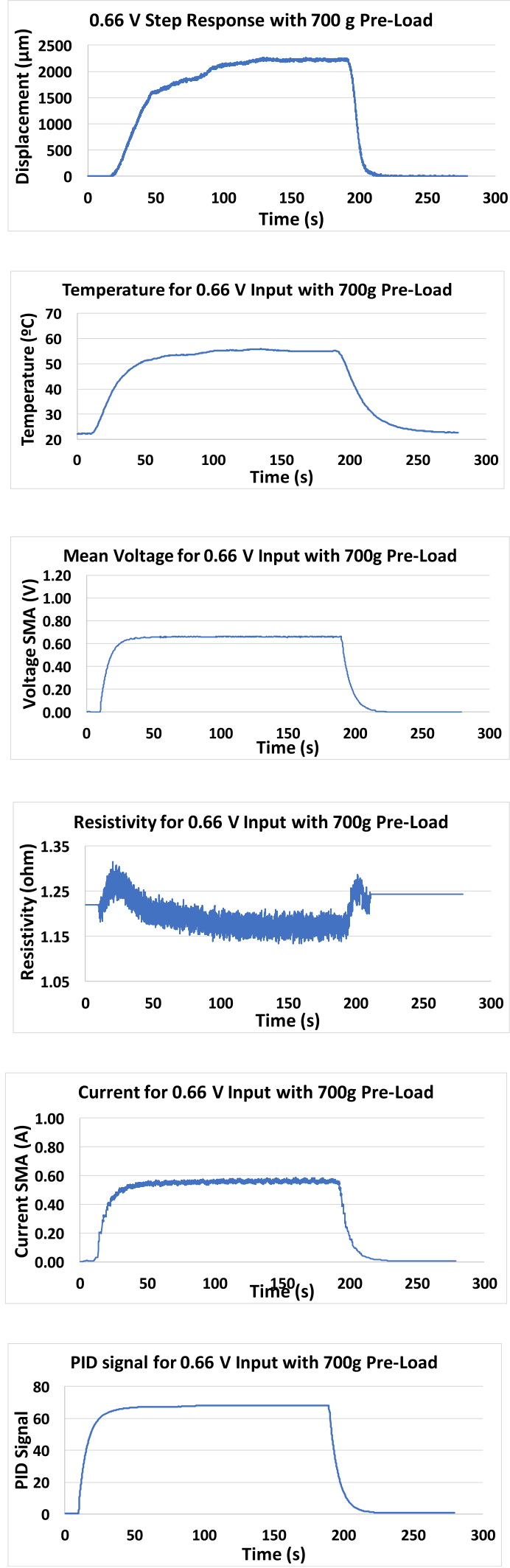

Fig. 14 Step response for displacement feedback and self-sensing feedback system with pre-loading of $700 \mathrm{~g}$ 
Publisher's Note Springer Nature remains neutral with regard to jurisdictional claims in published maps and institutional affiliations. 